\title{
POR OUTRA EDUCAÇÃO FÍSICA ESCOLAR: NATUREZA, CULTURA E EXPERIÊNCIAS NA COSTA DA LAGOA (SC)
}

\author{
Miraíra Noal Manfroi \\ Universidade Federal de Santa Catarina, Florianópolis, Santa Catarina, Brasil \\ Jairo Roberto Paim Ferreira \\ Prefeitura de Florianópolis, Florianópolis, Santa Catarina, Brasil
}

\author{
Alcyane Marinho \\ Universidade do Estado de Santa Catarina, Florianópolis, Santa Catarina, Brasil
}

\begin{abstract}
Resumo
Esta pesquisa se desenvolveu em uma escola pública municipal, pertencente a um bairro de Florianópolis (SC), Costa da Lagoa (Costa), no qual o acesso se faz somente por trilhas ou barcos. Parte de uma pesquisa mais ampla, este estudo etnográfico teve como objetivo investigar como ocorrem as aulas de Educação Física na Escola da Costa. Na escola estudada, pela criatividade do professor e a adesão das crianças, o próprio cenário da comunidade e da escola tornam-se espaços desafiadores para novas aprendizagens. O professor de Educação Física, ao planejar as aulas, envolve os recursos ofertados pela própria comunidade e pela natureza, ampliando a concepção de Educação Física escolar e de cultura corporal.
\end{abstract}

Palavras-chave: Educação Física. Escola. Natureza. Crianças.

\section{Preparando para ir à escola...}

Devido à extensão territorial, à diversidade natural e cultural, dentre outros fatores, a Educação Física escolar no Brasil possui diferentes nuances e características, quando comparada a de outros países. Neste contexto, esta pesquisa se desenvolveu em uma escola pública municipal, pertencente a um bairro de Florianópolis, Costa da Lagoa (Costa), no estado de Santa Catarina, sul do Brasil. Com suas montanhas cercadas de águas e suas cachoeiras, este bairro pode ser descrito como um singular espaço ao qual se tem acesso somente por meio dos barcos, que fazem as travessias, ou das trilhas que cruzam as montanhas, atravessando as matas. Neste local pitoresco cercado por uma natureza abundante, habitado por seres impregnados de suas humanidades, com qualidades e limites, o tempo que define o dia e a noite apresenta ritmo próprio, sendo possível ouvir ao longe o ranger dos motores dos barcos, o cantar das cigarras, crianças brincando em todas as partes, até em cima dos telhados, pelos sorrisos, pelas trocas de olhares e cumprimentos de acordo com a posição do sol e da lua: "Bom Dia!"; "Boa tarde!"; "Boa noite!”.

Nas águas que banham a Costa, são gestados os frutos do mar que, transformado em deliciosos pratos pelas mãos dos cozinheiros e cozinheiras, atraem turistas para os reconhecidos restaurantes - uma das fontes de renda mais significativas desse lugar. Além dos treze restaurantes e casas dos moradores, este bairro possui três lojas de artesanato, um pequeno mercadinho, uma igreja católica, um salão paroquial, uma unidade de saúde e uma 
escola, foco deste recorte. Tal escola atende crianças da comunidade e de locais próximos, da creche até o quarto ano do ensino fundamental. Possui funcionários e professores que moram na comunidade, mas também alguns que residem em outros locais. A maioria das crianças da Costa estuda ali até o quarto ano e somente depois deste período se transfere para outras escolas. No entanto, várias destas crianças, no contra turno de estudo formal, visitam a sua antiga escola e adoram ficar por ali, lanchar e conversar com os professores no intervalo.

Nesta dinâmica, a escola, para a comunidade, é um espaço para além do oferecimento do ensino formal, mas também um local de apoio e favores, pois muitos aparecem para pedir ajuda na leitura de algum documento, para fazer breves pesquisas nos computadores e suprir outras eventuais necessidades. Nesta região, as crianças só conseguem chegar por trilha ou por barco, não havendo estradas. Além disso, as condições físicas da escola e seus arredores são peculiares: não possui quadra poliesportiva; há um campo de grama e areia ao lado; existe uma lagoa de grande extensão em sua frente; e é cercada por uma reserva natural constituída de montanhas com matas.

Com base nestas considerações, o objetivo deste estudo, parte de uma pesquisa mais ampla, foi investigar como ocorrem as aulas de Educação Física na escola da Costa. O interesse pelo registro desta experiência se justifica na metodologia desenvolvida pelo professor de educação física escolar, pois, sem negligenciar os conteúdos, consegue ampliar as práticas corporais em diálogo com a cultura local e os espaços externos à escola. As crianças se exercitam e se encantam ao serem desafiadas a estar na e com a natureza. Assim, uma aula de Educação Física pode acontecer nas águas da lagoa, em cima de uma árvore, no pátio da escola, no verde campinho, nas subidas e nas descidas das montanhas, na liberdade de ser e de estar criança.

\section{Chegando à escola...}

Este artigo é fruto de uma pesquisa mais ampla, que teve como objetivo geral desvendar os sentidos e os significados encontrados nas relações estabelecidas pelas crianças, moradoras da Costa da Lagoa em Florianópolis (SC), entre o ser, o brincar e a natureza (MANFROI, 2015). Para este texto, o foco foi dado às aulas de Educação Física na escola da Costa. Com o intuito de conseguir permanecer o máximo de tempo no campo de pesquisa, para compreender seus significados e pormenores, a pesquisa foi fundamentada na etnografia, método científico que visa descrever um grupo ou uma cultura a partir de observações sistemáticas e participativas, complementadas por conversas informais e outros recursos que possibilitem compreender uma determinada cultura em suas manifestações cotidianas, visto que a vida diária se apresenta como grande potencialidade de movimentos transgressores e criativos, sendo capaz de se ressignificar e de buscar outras formas de viver (GEERTZ, 1989; MARINHO, 2003). A descrição feita ao longo do tempo em campo pretendeu ser holística, sendo que cada momento observado se compunha como uma unidade e não apenas a soma das partes, mas um organismo que se articula como um todo. A etnografia não buscou verdades ou mentiras, certo ou errado, mas, sim, os detalhes que se apresentam no cotidiano social e estes formam as informações coletadas, registradas e interpretadas (TRICHÊ; MORETTI-PIRES, 2012). A pesquisa manteve uma predominância qualitativa, sendo de caráter descritivo, desta forma buscamos apresentar os fenômenos sem a preocupação de generalizar os dados e tampouco de inserir variáveis no cotidiano investigado, mas, sim, de perceber sutilezas, delicadezas, conflitos e significados que fazem parte do contexto estudado (MINAYO, 1996, 1999). 
Considerando que a pesquisa proposta pressupõe interfaces entre a Educação Física escolar e as ciências humanas e sociais, é importante ressaltar, como afirma Minayo (1996, p. 15) que: “[...] as Ciências Sociais, [...], possuem instrumentos e teorias capazes de fazer uma aproximação da suntuosidade que é a vida dos seres humanos em sociedade, ainda que de forma incompleta, imperfeita e insatisfatória.". Nesta afirmação, são apontados os possíveis limites da pesquisa e a sua provisoridade histórica e científica, mas, ao mesmo tempo, indicam-se as possibilidades de fidedignidade na coleta e na interpretação dos dados.

A escolha da etnografia se justificou pelo objetivo da pesquisa que evidencia a necessidade de estar no campo de estudo para viver o cotidiano o mais próximo possível das crianças e do professor de Educação Física com o mínimo de interferência possível. Magnani $(1998,2002)$ apresenta em seus estudos, realizados com jovens, o princípio de transformar "o olhar de longe e de fora" no "olhar de perto e de dentro", com a compreensão de que nossa subjetividade faz parte de todo o processo. Em sintonia com esta proposta, a pesquisadora morou na comunidade investigada por três meses (de maio à julho de 2014) e, mesmo depois de se mudar, permaneceu acompanhando as aulas de Educação Física que aconteciam durante as manhãs e tardes das quintas feiras até o final do ano letivo.

Como em etnografia não se faz o uso de testes ou instrumentos baseados em respostas, comportamentos ou performances esperadas a priori, o caderno de apontamentos torna-se inseparável do pesquisador, com o intuito de não se perder detalhes que podem parecer insignificantes, mas que, ao se relacionarem com outros fatos e instrumentos, podem evidenciar significativas particularidades do grupo estudado. Além do caderno de apontamentos, foram utilizados outros instrumentos, não de maneira isolada, mas em um continuum: observações participantes, conversas informais, registros fotográficos e filmagens.

O foco das observações foram as aulas desenvolvidas em espaços e tempos da comunidade, junto a natureza, sem, no entanto, descartar os espaços e os tempos nos limites da escola. Nesta busca, definiu-se como "atividades na natureza", aquelas realizadas na terra, na água ou no ar, diferenciando-se dos esportes tradicionais, por possibilitar uma fluidez entre os praticantes e o meio ambiente (MARINHO, 2004).

Nesta perspectiva, foram participantes as crianças, alunas da escola, que se mostraram disponíveis, após os responsáveis receberem as informações necessárias para compreender os objetivos da pesquisa, as possíveis implicações em suas vidas e assinarem o Termo de Consentimento Livre e Esclarecido (TCLE) atendendo aos princípios éticos estabelecidos pela Resolução 466/2012, do Ministério da Saúde. ${ }^{121}$ Assim como a diretora, o professor de Educação Física participou, mas com outra conotação, pois foi pesquisado e pesquisador, praticante e problematizador da própria prática, contribuindo com a compreensão mais detalhada da proposta metodológica. Portanto, após um refinamento teórico sobre o objeto a ser estudado, as aulas de Educação Física foram acontecendo em espaços e tempos variados, como momentos privilegiados de trocas, de construção de processos educacionais mais humanos e sensíveis, por meio dos quais é possível, no coletivo, aprender, desaprender e reaprender.

${ }^{121} \mathrm{O}$ projeto de pesquisa, no qual este estudo estava inserido, foi submetido à análise do Comitê de Ética da Universidade do Estado de Santa Catarina, sendo recomendado com o Parecer Consubstanciado $\mathrm{N}^{\mathrm{o}}$ $701.067 / 2014$. 


\section{Aulas de Educação Física...}

As observações participantes nas aulas de Educação Física possibilitaram constatar que as próprias circunstâncias geográficas, tão diversificadas e, aparentemente, desfavoráveis, possibilitam diferentes abordagens metodológicas e conteúdos instigantes e provocadores de aprendizagens. Na escola estudada, não existe quadra poliesportiva. Quando as aulas acontecem do lado de dentro dos muros, são desenvolvidas no pátio de areia, que fica bem no centro da escola, ou então na própria sala de aula em dias de chuva. Quando acontecem do lado de fora são realizadas em um campo gramado que fica ao lado da escola, na lagoa ou nas proximidades da cachoeira. Para que se compreenda melhor a configuração dos espaços, é importante destacar que as condições geográficas, entre a lagoa e as montanhas, deixam uma estreita faixa livre e relativamente plana para o desenvolvimento das aulas. O que poderia ser apresentado como um elemento dificultador ou impeditivo torna-se caminho para conhecer e exercitar o corpo, na medida em que se nota um exercício constante do professor para ampliar o acesso aos locais da comunidade no intuito de desenvolver a cultura corporal.

O professor, neste caso, abdicou do autoritarismo em busca de ser companheiro dos alunos, sem descuidar de suas responsabilidades profissionais e sem deixar de planejar as suas aulas com vistas ao crescimento e às aprendizagens necessárias aos seus alunos. A formação inicial do professor em questão se deu em uma universidade pública do Rio Grande do Sul. $\mathrm{Na}$ continuidade, cursou especialização em Educação Física e depois de alguns anos optou por cursar mestrado em Ciência do Movimento Humano em uma universidade pública de Santa Catarina, investigando a saúde escolar e as implicações na aprendizagem. Atualmente é professor efetivo da Prefeitura Municipal de Florianópolis. Este percurso formativo, somado às suas buscas e características pessoais, encontrou o lugar e a escola abertos para aplicar as suas concepções pedagógicas nas aulas de Educação Física. As concepções estão baseadas principalmente no multiculturalismo crítico $^{122}$ que reconhece e utiliza o contexto geográfico explorando seu entorno, que valoriza as histórias e significados das formas de vida de onde a escola está inserida, e que também possibilita e apoia o intercâmbio entre culturas; tendo como intuito validar as vozes da comunidade, rejeitar o elitismo e entender a elaboração constante de um projeto democrático para a sociedade, no qual todos efetivamente tenham vez (NEIRA, 2011).

A escola da Costa é diferenciada, pois está localizada às margens da lagoa, permitindo que as crianças, do pátio ou de dentro de algumas salas de aula, possam contemplar as águas. Esta proximidade constitui a lagoa como parte do cotidiano e amplia os espaços e os tempos escolares. Somando-se a este fato, é necessário destacar a relação de trocas que se estabelece entre a escola e a comunidade, tornando muito tênue os limites do que é somente escolar e do que é escolar, mas também da comunidade. Nesta dinâmica, é comum os portões da escola se abrirem para passeios, brincadeiras e, neste caso específico, para as aulas de Educação Física,

${ }^{122}$ O multiculturalismo surge no hemisfério norte, após a segunda guerra mundial, devido ao intenso fluxo migratório, gerando uma nova configuração social e forçando a convivência dos diferentes, e ampliando o contato de culturas distintas. Os estudiosos que o estudaram e o estudam dividem-no em três tipos de multiculturalismo: conservador; assimilacionista e intercultural/crítico. Neste artigo tratamos especialmente do crítico que visa compreender as razões de opressão, construção das desigualdades, diferenças e estereótipos; e acredita no diálogo e no hibridismo (na mistura / fusão de culturas que acabam por esse processo se renovando) entre culturas como uma das maneiras de fazer o rompimento com a educação moderna, a qual acredita que a discriminação e o preconceito cultural não podem ser extintos do mundo social (NEIRA, 2011). 
pois como evidencia Santos (2013, p. 52): "Tudo o que acontece na comunidade se estende para o espaço da escola e tudo o que acontece na escola abre-se para a comunidade, numa relação de interdependência.".

Nesta perspectiva, durante a pesquisa, pode-se acompanhar a oficina de prancha ecológica. Neste dia, pais, crianças, professores e funcionários da escola puderam experimentar as etapas de construção ao utilizarem garrafas pet, cano, cola e gelo seco. Como a comunidade e a escola se encontram muito próximas da lagoa, os diferentes meios de estar sobre as águas chamam muito a atenção. É como se as crianças e os moradores fossem seres das águas, fato que não foi diferente no dia da confecção e da experiência de utilizar a prancha. Praticamente todas as crianças e seus responsáveis ouviram atentos, acompanharam as explicações e aprenderam, fazendo, o passo a passo da construção do equipamento esportivo. Logo após a conclusão todos foram convidados a se deslocar até a lagoa para experimentar a prancha ecológica. Os coordenadores da oficina levaram outras pranchas para possibilitar que os alunos pudessem sentir as diferenças e semelhanças entre a construída e os outros tipos. Dentre distintas possibilidades reflexivas originárias desta experiência vivida, possivelmente a resistência em participar e as manifestações de indisciplina podem ser minimizadas com aulas criativas, envolventes e relacionadas com a cultura e a natureza do lugar.

Em outro dia da aula de Educação Física, mais ensolarado, com menos nuvens e vento, o professor levou as crianças para o gramado que fica ao lado da escola e montou um espaço destinado para jogar bola. Colocou duas goleiras, quando tudo parecia conduzir para o jogo que se iniciava, surgiu outra atração. Havia neste mesmo terreno um barco, que por não servir mais para a pesca, foi transformado em floreira. Neste barco estava amarrado um boi. Logo que o primeiro chute foi dado, a bola parou embaixo do boi. As crianças muito afoitas e entusiasmadas começaram a articular uma maneira de pegar a bola. Logo o professor de Educação Física as ajudou, aproximou-se do cantinho do barco que estava o boi amarrado e deu mais algumas voltas na corda, afastando o boi da bola, que logo foi resgatada. Mas, com um boi presente, quem quer jogar futebol? Naquele dia, a tentativa de "conversar" com o boi durou a aula inteira. Na sequência, os coletes, usados normalmente para diferenciar os times, passaram a ser movimentados com a intenção de fazer o boi sair correndo atrás deles. A brincadeira foi longe com risadas, tentativas de aproximação, e cuidados de alguns que seguravam os colegas para não se aproximarem muito.

Observando o desenrolar da aula que, aparentemente, mas só aparentemente, não atingiu os objetivos, foi possível dialogar com a concepção de experiência apresentada por Larossa (2015, p. 30-31): "O que ocorre é que se trata de um saber distinto do saber científico e do saber da informação, e de uma práxis distinta daquela da técnica e do trabalho. O saber de experiência se dá na relação entre o conhecimento e a vida humana.". O mesmo autor evidencia que, a partir de acontecimentos comuns, a experiência se dá de maneira singular para cada um de nós e, portanto, é impossível de ser repetida, pois, permeada pela dinâmica da vida, foge ao que foi planejado. Assim, o jogo de futebol virou brincadeira entre as crianças e o boi. Provavelmente ficará na memória dos que a viveram e será rememorada em muitas narrativas.

Em outro dia, ao chegar à escola, observei as crianças carregando colchonetes, cordas, arcos e outros materiais. Caminhavam em direção ao mesmo campo gramado. Aos poucos, e como quem já sabe o que e como fazer, os colchonetes foram colocados embaixo dos galhos mais grossos de uma árvore. Após o alongamento, as crianças se espalharam pelo campo, fazendo muito barulho e espalhando os materiais. Algumas crianças passaram a subir na 
árvore e a se jogarem sobre os colchonetes, outras pulavam corda, outras brincavam com os arcos. Foi bonito de observar e perceber a agilidade e harmonia nos movimentos, a alegria nos rostos e a serenidade como a aula se desenrolou. Ao final, as crianças com sede, descobriram uma árvore de limão e foi uma bagunça. As maiores subiram e as crianças menores esperavam embaixo para pegar as frutas. Esta aula cumpriu ao planejado, atingiu os objetivos, mas extrapolou os significados, pois chupar limão azedo trouxe muitas risadas e caretas.

Além da breve descrição destas três aulas, durante a pesquisa foram observadas práticas com slackline entre as árvores, caminhadas na busca de pássaros, jogos de sinais em cima dos trapiches, dança embalada por cantigas de roda, entre outras iniciativas criativas. Não foram observadas aulas repetitivas, tampouco foram desenvolvidas aulas voltadas para os conteúdos tradicionais da Educação Física escolar que, de maneira geral, têm buscado historicamente a disciplinação, os movimentos padronizados $\mathrm{e}$ o alto rendimento (OLIVEIRA, 2002). A proposta do professor, que não negligencia as atuais propostas da Educação Física escolar, traz a concepção e o objetivo de:

Ao romper com a violência da imobilidade sobre os corpos das crianças, ou ainda a da configuração de uma verdadeira cela de aula, tem-se a possibilidade de contribuir, considerando a concepção-ação pedagógica utilizada ao se movimentar, às aprendizagens que não se limitam a um desenvolvimento motor, e sim humano - transdisciplinarizador às questões das relações sociais impregnadas (gênero, classe social, orientação sexual, habilidade motora, lugar de origem, outras subculturas etc).

Neste depoimento o professor deixa clara a sua intenção de, por meio da Educação Física, ir além das questões que envolvem o desenvolvimento motor, na busca por uma formação holística das crianças, fato esse observado nas aulas acompanhadas e também relatado pela diretora sobre as aulas de Educação Física:

As aulas de Educação Física são essenciais, trabalhar o corpo, a questão da saúde, espaço, limites, regras, aprender a jogar de forma saudável, possibilidades, resistência, também influencia no aprendizado em sala de aula, em outras disciplinas e na relação da criança consigo mesma e com os outros ao seu redor. [...] concordava com a sua concepção, sua forma de dar aula dando mais ênfase ao movimento de um modo geral. Mas percebia falta de conhecimento das crianças sobre os esportes, acho isso necessário, não para conhecer só o jogo em si, mas aprender o movimento, a localização, regras, entre outras.

Podemos constatar, na fala da diretora, a preocupação com o aprendizado dos esportes e de suas regras, embora estes aprendizados se façam presentes, nas aulas, de maneira não tão direta. Esta interpretação pode ser compreendida pelo fato de que, efetivamente, há uma preocupação na equipe gestora e pedagógica da escola em proporcionar aos alunos um currículo que não se distancie das demais escolas da rede. Este cuidado tem alcançado seus objetivos, pois os egressos têm apresentado bom desempenho e boa adaptação na continuidade de suas trajetórias escolares. Onde existe a convivência humana existem contradições, e são elas que nos impulsionam para que, por meio do diálogo, consigamos avançar em nossas reflexões e práticas. Ao falar sobre as condições de espaço físico para o desenvolvimento das aulas o professor e a diretora concordam nos aspectos essenciais, mas divergem sobre a ausência de quadra: 
O espaço físico seria um fator limitador em qualquer lugar de aulas de EF. A escola da Costa da Lagoa, ainda que somente com um pátio de areia de aproximadamente $120 \mathrm{~m} 2 \mathrm{em}$ seu interior, o que já possibilita o desenvolvimento da maioria das atividades pertinentes, tem o privilégio dos seus arredores. Seus espaços, bem próximos, agregam possibilidades naturais e reservadas pela condição do lugar em seu isolamento/segurança em relação aos espaços urbanos. (Professor)

Acredito que não há limites, ainda temos um pátio, dentro e fora da escola, claro que se tivéssemos uma quadra poderia ser diferente, mas acredito que as aulas de Educação Física dependem do professor, do seu planejamento. Muitas vezes temos tudo para uma aula de Educação Física dar certo, mas se o professor não planejar, não adianta de nada ter um espaço. (Diretora)

$\mathrm{Na}$ continuidade, conversamos sobre as resistências encontradas pelo professor ao aplicar as suas concepções de cultura corporal nas aulas. Novamente fica evidente que as representações sociais associam, dialeticamente, a Educação Física a tempos e espaços de liberdade (alunos) e aos movimentos padronizados, aos esportes oficiais e aos métodos tradicionais de colunas, filas e outros (professores). De acordo com o professor, a resistência maior entre os alunos aconteceu inicialmente nos terceiros e quartos anos: "Talvez o maior desafio estivesse em ouvir as nossas conversas iniciais - eles queriam fazer suas coisas, eles queriam sair porta afora, eles queriam espaços e tempo para se desorganizar e, quem sabe, se organizar nas suas escolhas.”. No entanto, alguns colegas professores fizeram críticas e passaram a sugerir outras práticas formais, desconsiderando a experiência e o processo de observação/ conhecimento: "A questão que me vinha era sobre com que olhar/referencial surgiam tantas observações e sugestões?”. Já com os pais: ‘[...] em seus olhares curiosos, predominou a expectativa e o respeito para com o meu trabalho.”.

No decorrer das observações foi possível constatar que, apesar de todas as críticas que se possa fazer sobre os espaços, os tempos e as abordagens da Educação Física escolar, a metodologia utilizada nesta escola transgride e é caminho para algumas vivências corporais que se tornam escassas na atualidade, sendo muitas vezes necessária a persistência e a leitura do contexto em que se está atuando, pois como coloca o professor sobre a sua experiência de ministrar aulas nesta escola:

A percepção maior talvez tenha sido a de que o desenvolvimento humano tenha potencial determinante na interculturalidade. Tudo aquilo que se reserva fisicamente tenderá ao conservadorismo e à resistência ao novo. A vida fica limitada e as possibilidades serão desperdiçadas.

Outro fator significativo é a utilização de Guinho, um boneco de pano, durante as aulas de Educação Física. As crianças são convidadas a cuidar do boneco durante toda a aula. Assim, Guinho participa de todas as atividades, das rodas de conversa e das danças. Outro fator significativo é a utilização de Guinho, um boneco de pano, durante as aulas de Educação Física. As crianças são convidadas a cuidar do boneco durante toda a aula. Assim, Guinho participa de todas as atividades, das rodas de conversa e das danças. Esta condução é intencional e busca desmistificar os brinquedos feitos para meninas e para meninos: "Afinal, quem instituiu que meninos não brincam com bonecos ou bonecas de pano?". A partir desta provocativa pergunta pode-se perceber a preocupação em abordar as questões de gênero de 
uma maneira concreta, com a presença do boneco. O boneco está presente na escola há quatro anos e, provavelmente, esteja contribuindo para desconstruir preconceitos. Pode-se suspeitar que algumas cenas presenciadas durante a pesquisa tenham um pouco dessa ideia disseminada durante as aulas de Educação Física. Na Costa, as meninas jogam futebol junto com os meninos e os meninos brincam de construir casinhas com as meninas. Juntos descem as montanhas em secas cascas de coqueiros (cascudas), fazem travessias de barco, fazem travessuras. São crianças que ultrapassam os padrões tradicionais e os significados de serem meninas ou meninos.

Acompanhando a dinâmica escolar pode-se perceber que a escola possui materiais diferentes e alternativos para dinamizar as aulas de Educação Física e que auxiliam na maior diversificação dos conteúdos, além das tradicionais bolas de borracha, arcos, cordas, pernas de pau, colchonetes e alguns instrumentos musicais de percussão. Acrescentam-se a estes, as bolinhas de gude, o elástico, as traves de equilíbrio (madeiras), a prancha com mola, os apitos de pássaros, o slackline, a prancha de stand up, o skate de pneus e as oficinas de brinquedos com materiais recicláveis -construções de carrinhos eólicos, aviões, casinhas e bonecos entre outros. Estes materiais são transportados pelo professor e sempre com a cooperação das crianças para diferentes locais, de acordo com a hora do dia e as condições do clima. Para além destes materiais, nos espaços fora da escola, bancos viram tábuas de equilíbrio, galhos de árvores servem para subir, pendurar-se, balançar e soltar-se/cair nos colchões, cachorros soltos viram pegadores no jogo de pegar.

Assim, pela criatividade ora do professor, mas também das próprias crianças e a adesão decorrente do grupo, as contribuições imediatas muitas vezes eram inseridas e os próprios cenários da comunidade e da escola tornavam-se espaços desafiadores para novas aprendizagens. Numa dada aula, o grupo de $3^{\circ}$ e $4^{\circ}$ anos juntos, não só brincou com as bolinhas de gude, mas iniciou a construção de um estádio para jogá-las. Isto ocorreu de maneira tão espontânea, com todos que ali brincavam, que qualquer outro conteúdo planejado teria sido uma violência para com aquele momento pedagógico efervescente - cooperação a nivelar a areia do piso, procura de madeiras improvisadas para servirem como pás e a própria limpeza realizada por eles, os adornos do estádio com bonequinhos plásticos, o portão de entrada, os buracos da área de jogo, o estacionamento das bolinhas e o jogar em si. Portanto, o professor de Educação Física usou os recursos ofertados pela própria comunidade e pela natureza em seu planejamento, ampliando e intensificando a concepção de Educação Física escolar e de cultura corporal.

\section{Voltando da aula de Educação Física...}

Este estudo evidenciou que o professor de Educação Física da escola estudada, ao ampliar os espaços das suas aulas para além dos muros institucionais, proporciona aos seus alunos o encontro com árvores, trilhas, bichos, águas, permitindo refletir sobre a existência das diversas possibilidades de trabalhar a cultura corporal com atividades diferenciadas e relacionadas com a natureza (CORNELL, 1996). Além do processo educacional destas crianças estar sensibilizado para questões mais amplas do que os conteúdos, a comunidade é beneficiada na medida em que ocorre o envolvimento desta escola pública com os espaços e os tempos locais, sendo possível sonhar com mais organização e limpeza, com mais árvores e flores, com mais águas e peixes.

Espaços esteticamente mais bem planejados e cuidados que, gradativamente, possam mudar a vida de todos. Sendo assim, a escola, ao ampliar seu cotidiano para outros espaços 
públicos e possibilitar experiências educativas brincantes, está contribuindo com a construção de uma cultura que aproxime e misture idades, gêneros, experiências, conhecimentos, crenças, esperanças, entusiasmos, alegrias, tristezas, decepções, vidas.

Assim, o professor de Educação Física neste contexto específico, ao levar as crianças para fora dos limites da escola, além da possibilidade de desenvolver os conteúdos mais variados da cultura corporal, em ambientes diversificados, proporciona aos seus alunos o desenvolvimento motor, psicológico e social norteados pela perspectiva que entende as crianças como seres capazes, sociais e históricos (PRADO, 2012), construindo um processo educacional diferenciado em uma sociedade na qual, como afirma Marcellino (2005, p. 59), as crianças, em sua maioria, convivem com a "[...] impossibilidade de vivência do presente, em nome da preparação para um futuro que não lhes pertence.”.

Para assegurar o direito das crianças viverem as suas infâncias e a sua cultura corporal nos processos de escolarização se faz necessário o intercâmbio de professores que trabalham em diferentes contextos na área da Educação Física e nas demais áreas de formação. Estas trocas podem ajudar a fortalecer o leque de oportunidades ofertado e construído com as crianças durante as aulas, na busca de um planejamento educacional mais humano e sensível. Para tanto, a oportunidade de encontros dos próprios professores para além dos muros da escola também se faz necessária, para que o olhar da Educação Física escolar seja ampliado e mantenha uma dinâmica que permita o seu constante envolvimento na melhoria da vida dos alunos e das comunidades em que estão inseridos.

No caso específico apresentado neste artigo, a formação continuada do professor se constitui fator marcante para uma experiência de atuação profissional que ultrapassa as concepções e as representações sociais do que se espera das aulas de Educação Física escolar, pois, conforme apontam Neira e Nunes (2006), esta responsabilidade é pedagógica, mas também política e social. Os mesmos autores, na mesma obra, evidenciam que, ao estabelecer pontes de mão dupla com o seu entorno, as escolas públicas e os professores que nelas atuam estarão, intencionalmente, reconhecendo que os saberes populares e os jeitos de viver das comunidades (gestualidades, historicidade, estética, formas de ser e de pensar) são tão significativos para a vida social quanto os conteúdos escolares.

Evidencia-se, desta forma, o encontro de uma proposta educacional coerente com o contexto, com as suas crianças, com os tempos e os espaços escolares e comunitários, perpassando a estreita relação com o ambiente natural. É possível pensar em outros caminhos educativos. A escola e os professores - de Educação Física e de outras as áreas -, quando estão imbuídos de sua função social, podem somar-se à cultura local, ampliando as possibilidades de aprender e de ensinar, privilegiando as experiências (BENJAMIN, 1980, 2012; LAROSSA, 2015) e o coletivo.

No entanto, é preciso ressaltar que esta proposta é inovadora e que não se faz presente na maioria das escolas públicas e nas aulas de Educação Física. Pensar, planejar e desenvolver mudanças pedagógicas nestas aulas exige a construção de uma matriz epistemológica que oriente e fundamente as escolhas de conteúdos, a preparação dos espaços e dos materiais e a metodologia a ser desenvolvida, pois atuar com crianças exige cuidados preventivos. Desafiar, instigar, ultrapassar limites e vencer medos são caminhos essenciais, mas respeitando o tempo e as habilidades de cada criança. Neste caso, a sensibilidade e a experiência do professor, somadas aos seus conhecimentos teóricos, serão balizadores de sua práxis.

A proposta apresentada neste artigo não se constitui como um modelo e tampouco pode ser aplicada indiscriminadamente em outras escolas, pois o local, os atores e os contextos são muito singulares. Para que, então, efetivamos este registro? Para evidenciar que 
há caminhos possíveis para a construção de uma Educação Física escolar que dialogue com a cultura local, com as famílias, com as crianças, com as demais áreas do conhecimento, com a natureza. Uma Educação Física escolar que se estenda para além das quadras esportivas, para além dos esportes e suas regras, para além do endireitamento dos corpos, para além dos movimentos padronizados para todos. Uma Educação Física escolar livre, alegre, brincante, com desaprendizagens e aprendizagens, sempre em movimento, mas com direito ao nada fazer, da vida e pela vida.

\begin{abstract}
This research was developed in a public school, belonging to a neighborhood Florianópolis (SC), Costa da Lagoa (Costa ), in which the access is only through tracks or boats. Part of a broader research, this ethnographic study aimed to investigate how to place the Physical Education classes at the School of the Coast. Studied in school, the teacher creativity and adherence of children, the very community setting and school become challenging areas for new learning. Professor of Physical Education, plan lessons, involves the resources offered by the community and nature, expanding the concept of Physical Education and body culture.
\end{abstract}

Keywords: Physical Education. School. Nature. Children.

\title{
Resumen
}

Esta investigación se ha desarrollado en una escuela pública del municipio, que pertenece a un barrio de Florianópolis (SC), Costa da Lagoa (Costa), en la que el acceso sólo es posible a través de pistas o barcas. Parte de una investigación más amplia, este estudio etnográfico tuvo como objetivo investigar cómo ocurren las clases de Educación Física en la Escuela de la Costa. En la escuela mencionada, debido a la creatividad docente y a la adhesión de los niños, el propio escenario de la comunidad y de la escuela se convierten en espacios desafiadores para nuevos aprendizajes. El profesor de Educación Física, al planificar las clases, abarca los recursos que ofrece la comunidad y la naturaleza, ampliando el concepto de Educación Física y de cultura del cuerpo.

Palabras clave: Educación Física. Escuela. Naturaleza. Niños.

\section{Referências}

BENJAMIN, W. (1892-1940) Magia e técnica, arte e política: ensaios sobre literatura e história da cultura. 8. ed. rev. São Paulo: Brasiliense, 2012 (Obras Escolhidas v. 1).

BENJAMIN, W. Textos escolhidos. In: BENJAMIN, W. et al. Textos escolhidos. São Paulo: Abril Cultural, 1980. p. 1-85.

BRASIL. Resolução $\mathbf{N}^{\mathbf{0}}$ 466, de 12 de dezembro de 2012. Dispõe sobre dignidade humana e pela especial proteção devida aos participantes das pesquisas científicas envolvendo seres humanos. Disponível em: <http://conselho.saude.gov.br/resolucoes/2012/Reso466.pdf $>$. Acesso em: 24 ago. 2013.

CORNELL, J. Brincar e aprender com a natureza. São Paulo: Melhoramentos, 1996.

GEERTZ, C. A interpretação das culturas. Rio de Janeiro: LTC,1989. 
LAROSSA, J. Tremores: escritos sobre experiência. Belo Horizonte: Autêntica, 2015.

MAGNANI, J. G. C. De perto e de dentro: notas para uma etnografia urbana. Revista Brasileira de Ciências Sociais, São Paulo, v. 17, n. 49, p. 11-29, jun. 2002.

MAGNANI, J. G. C. Festa no pedaço: cultura popular e lazer na cidade. 2. ed. São Paulo: Hucitec/UNESP, 1998.

MANFROI, M. N. Ser criança na Costa da Lagoa: Memórias, brincadeiras e natureza. 2015. 331 f. Dissertação (Mestrado em Educação Física) - Centro de Desportos, Universidade Federal de Santa Catarina, Florianópolis, 2015.

MARCELlinO, N. C. Pedagogia da animação. 7. ed. Campinas: Papirus, 2005.

MARINHO, A. Atividades na natureza, lazer e educação ambiental: refletindo sobre algumas possibilidades. Motrivivência, Florianópolis, n. 22, p. 47-70, jan. 2004.

MARINHO, A. Da aceleração ao pânico de não fazer nada: corpos aventureiros como possibilidade de resistência. IN: MARINHO, M.; BRUHNS, H. T. (Org.). Turismo, lazer e natureza. São Paulo: Manole, 2003. p. 01-28.

MINAYO, M. C. de S. O desafio do conhecimento: pesquisa qualitativa em saúde. 6. ed. São Paulo: Hucitec, 1999.

MINAYO, M. C. de S. (Org.) Pesquisa social: teoria, método e criatividade. 5. ed. Petrópolis: Vozes, 1996.

NEIRA, M. G. O currículo cultural da Educação Física em ação: a perspectiva dos seus autores. 2011. 333 f. Tese (Livre docência em Metodologia do Ensino da Educação Física) Faculdade de Educação, Universidade de São Paulo, São Paulo, 2011.

NEIRA, M. G.; NUNES, M. L. F. Pedagogia da cultura corporal: crítica e alternativas. São Paulo: Phorte, 2006.

OLIVEIRA, M. A. T. Educação Física escolar e ditadura militar no Brasil (1968-1984): história e historiografia. Educação e Pesquisa, São Paulo, vol. 28, n.1, pp. 51-75. Jan./Jun. 2002.

PRADO, P. D. Educação e culturas infantis: crianças pequenininhas brincando na creche. São Paulo: Képos, 2012.

SANTOS, R. Olhar pelas fronteiras - o diálogo estético entre esferas sociais. 2013. 179 f. Dissertação (Mestrado em Educação) - Centro de Ciências da Educação, Universidade Federal de Santa Catarina, Florianópolis, 2013. 
TRICHÊ, P. B. M.; MORETTI-PIRES, R. O. Pesquisa etnográfica. In: SANTOS, S. G. dos; MORETTI-PIRES, R. O. Métodos e técnicas de pesquisa qualitativa aplicada à Educação Física. Florianópolis: Tribo da Ilha, 2012. p. 105-111.

Recebido em: 25/05/2015

Revisado em: 27/07/2015

Aprovado em: 31/08/2015

Endereço para correspondência:

Miraíra Noal Manfroi

mira_nm@hotmail.com

Universidade Federal de Santa Catarina

R. Eng. Agronômico Andrei Cristian Ferreira, s/n

Trindade, Florianópolis - SC, 88040-900 